\title{
Los ardides de Clitemnestra en el tercer episodio de Agamenón de Esquilo
}

\section{Cecilia J. Perczyk}

Universidad Nacional de Hurlingham, Instituto de Educación; Universidad Nacional de San

Martín; Universidad de Buenos Aires, Argentina

cecilia.perczyk@unahur.edu.ar

\author{
Lara Seijas \\ Universidad Nacional de Hurlingham, Instituto de Educación; Universidad del Cine; Universi- \\ dad del Museo Social; Universidad de Buenos Aires, Argentina \\ laraseijass@gmail.com
}

Fecha de recepción: 30/03/2020. Fecha de aceptación: 06/08/2020

\begin{abstract}
Resumen
En el presente trabajo nos proponemos analizar estrategias discursivas y performáticas en tensión con el modo de configurar los géneros sexuales en el tercer episodio de la tragedia Agamenón de Esquilo. La escena, lejos de ser un emotivo reencuentro entre los esposos, se compone de una serie de resignificaciones acerca de lo que se espera de un hombre y una mujer en la Antigua Grecia. Nos enfocaremos en el estudio de los elementos que sostienen y subvierten el papel de Clitemnestra con el objetivo de aportar datos para la comprensión de la figura de la reina, en tanto andrógina, y la implicancia en términos políticos de sus actos.
\end{abstract}

Palabras clave: Tragedia griega, Esquilo, Agamenón, Géneros sexuales, Androginia.

\section{Clytemnestra's tricks in the third episode of Aeschylus' Agamemnon}

\begin{abstract}
This work seeks to analyze the discursive and interpretative strategies associated to the distribution of gender roles in the third episode of Aeschylus' tragedy Agamemnon. The scene, far from being an emotional reunion between the spouses, consists of a series of resignifications regarding what is expected of a man and a woman in Ancient Greece. We will focus on the study of the elements that support
\end{abstract}


and subvert the role of Clytemnestra, in an attempt to understand the queen's figure and her androgynous attributes, as well as the political implication of her actions.

Keywords: Greek Tragedy, Aeschylus, Agamemnon, Gender, Androgyny.

Aeschylus' theatrical masterstroke is to put the battlefield in visible spatial terms before the spectator'eyes (Taplin, 1977).

\section{Introducción}

La producción trágica de Esquilo, a través del discurso y la representación escénica, problematiza el papel de la mujer en la Atenas del s. V a. C. y da cuenta de una profunda escisión en la distribución de los roles sexuales en la sociedad. Partimos de una serie de supuestos teóricos que sustentan nuestra investigación. En primer lugar, asumimos que el género sexual no constituye algo existente en los seres humanos, sino que es el conjunto de efectos producidos en los cuerpos, los comportamientos y las relaciones sociales como consecuencia del despliegue de una tecnología política (De Lauretis, 1989: 8, entre otros). En segundo lugar, es importante tomar en cuenta a la hora de analizar dramas griegos que se trata de producciones escritas por poetas varones para actores hombres, que representaban personajes masculinos y femeninos y estaban dirigidas a un público compuesto, en su mayoría, por hombres, lo que promovió en la audiencia una reflexión sobre el papel determinado para cada sexo. El teatro de Esquilo resulta sumamente oportuno para el estudio de las configuraciones ideológicas de la distinción entre lo masculino y lo femenino dentro de la sociedad griega porque mantiene la división de los sexos en pos de una organización jerárquica del poder. Además de proporcionar la estructura de las obras, el enfrentamiento de hombres y mujeres se materializa en la puesta en escena ya que las posturas dramáticas de los personajes presentan contrastes (Zeitlin, 1990: 103).

Agamenón es la primera obra de la trilogía de Esquilo la Orestía, que -seguida por el drama satírico Proteo, obra perdida para nosotros- se estrenó probablemente en el 458 a. C., poco tiempo después de la reforma de Efialtes, que implicó una disminución del poder otorgado al Areópago, institución cuyo origen se representa en el final de Euménides, la última obra de la trilogía.

En la tragedia se representa el regreso del rey a la ciudad de Argos, luego de la guerra de Troya. Lo espera Clitemnestra, la esposa, que planificó minuciosamente su muerte. En el presente trabajo nos enfocaremos en el tercer episodio de la tragedia (vv. 810-974), que se compone, desde lo retórico y desde lo performático, de una serie de inversiones, ambigüedades y resignificaciones que permiten configurar a Clitemnestra como un personaje andrógino. ${ }^{1}$

El encuentro entre los esposos, tras la llegada del rey a la ciudad de Argos, soporta $\mathrm{y}$, a la vez, transgrede la distribución hegemónica de los papeles de que debían cumplir los hombres y las mujeres de la época. Los transgrede en tanto Clitemnestra, mediante el discurso, se autoconfigura y, al mismo tiempo, es configurada como un hombre por Agamenón. Los soporta, por otra parte, en tanto sus parlamentos apelan a la persuasión engañosa y al discurso ritual, dos formas de la palabra asociadas a la mujer (para un breve recorrido sobre la función de la mujer en los siglos $\mathrm{V}$ y IV a. C. y su representación en la escena trágica, cfr. Foley (2001: 109-144)). La 
oscilación configura a la heroína como un personaje ambivalente desde el punto de vista de los géneros sexuales. Su androginia (el sustantivo androginia, cualidad

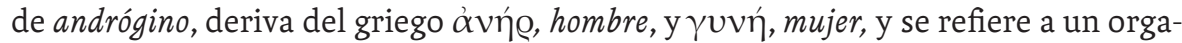
nismo que tiene características tanto masculinas como femeninas) se materializa cuando en la tragedia la tarea femenina de tejer queda resemantizada: los tejidos que manipula son las redes que portan la muerte de su marido. Entendemos que la resignificación se vincula más con su voluntad de poder y con el poder que ella posee -en efecto, gobernó la ciudad durante los diez que se ausentó su maridoque con la venganza por el sacrificio de Ifigenia y el ingreso de Casandra al palacio como concubina del rey. ${ }^{2}$

\section{Los rasgos masculinos de Clitemnestra en tensión con los destinatarios de sus palabras}

Winnington-Ingram (1948: 130-147) vincula la independencia de pensamiento y la capacidad de acción de la reina con su deseo de gobernar, y McClure (1999: 73) señala que, desde el plano discursivo, su androginia se significa por la yuxtaposición de términos vinculados a lo femenino y a lo masculino. En otras palabras, pero con el mismo sentido que el que se propone en este trabajo, Sevieri (1991: 14 y 18) señala que Clitemnestra usa un lenguaje consciente en tanto le permite intervenir sobre la realidad, se mueve sobre dos niveles de comunicación: el lógico y el metafórico.

Clitemnestra emplea estrategias retóricas y performáticas en su configuración genérica que funcionan persuasivamente teniendo en cuenta los diversos destinatarios de sus palabras. En un mismo parlamento y casi sin interrupciones, la reina se dirige al coro de ancianos, a Agamenón, a las sirvientas y, por supuesto, al público. La estrategia, sumada al tratamiento de su esposo en segunda persona del singular que se alterna con la tercera, es decir, como destinatario y como objeto, produce un juego de significaciones en el que no todos los personajes saben lo mismo. La articulación de múltiples referencias en escena, detectada por el espectador, genera nuevos sentidos en relación con los binomios masculino/femenino, griego/bárbaro, público/privado, que caracterizan a la cultura griega antigua.

La reina aparece en escena cuando Agamenón anuncia que se dirige hacia el hogar (v. 851), obstaculiza su ingreso al salir por la puerta del palacio y declamar un largo discurso (vv. 855-913). En principio, ella no se dirige al rey, sino que su primer interlocutor es el Coro, compuesto por ancianos argivos (vv. 855-876). El hecho de que sea un grupo compuesto por hombres (en verdad todos los personajes de la obra lo son, a excepción de Clitemnestra y Casandra, que entrará acompañando a Agamenón) la muestra como la única mujer portadora de palabra con valor político. En contraposición a la reina de Argos, Casandra, la princesa de Troya devenida en concubina de Agamenón, despliega discursos típicamente femeninos como, por ejemplo, el lamento y la oración y, además, se mantiene en silencio en gran parte de la tragedia, como era esperable que se condujera una mujer ateniense. De modo que, irónicamente, Casandra encarna el ideal de la mujer griega (Goldhill, 1984: 57-58). Doyle (2008) sostiene que Casandra en Agamenón actúa según los arquetipos sociales femeninos que quedan libres: como hija-víctima sacrificial ideal, porque va de forma voluntaria al altar de sacrificio, sin resistirse, a diferencia de Ifigenia; y como la esposa ideal, porque rechaza a Apolo (se desviste de sus ropas de sacerdotisa) para unirse a Agamenón. Esquilo muestra a la princesa troyana como una Ifigenia y Clitemnestra perfeccionadas.

2 Bierl (2017) entiende que Clitemnestra en Orestía se presenta como la versión femenina de Edipo en Edipo rey de Sófocles. Si bien coincidimos en varios puntos con su propuesta de análisis, consideramos que, al enfocarse en el aspecto masculino del personaje, deja de lado las implicancias de la parte femenina. 
Con su discurso, la reina busca persuadir a los ancianos de haber actuado según el comportamiento debido para los intereses del hogar y de la ciudad. Sin embargo, expresa la génesis autónoma de sus pensamientos y convicciones:

Les voy a contar, no por haberlo aprendido de otros, mi vida, difícil de soportar, durante el tiempo en que este hombre estuvo al pie de las murallas de llión. vv. 858-860.

oủk ä $\lambda \lambda \omega v \pi a ́ p a$

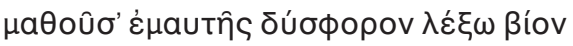

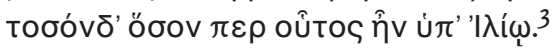

Clitemnestra exhibe su capacidad de manejar la dimensión masculina de la palabra y presentar un discurso organizado. Sin embargo, a continuación, asume una pose de vulnerabilidad y dependencia según lo conveniente para la mujer de la época:

En primer lugar, que la mujer esté sola en la casa sin su hombre es un mal terrible, porque escucha muchos rumores odiosos, y llega un mensajero, anunciando a gritos una calamidad para la casa, y en seguida se agrega otro, trayendo una nueva calamidad peor que la anterior. vv. 861-865.

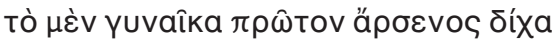

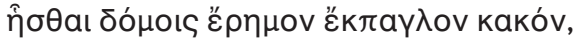

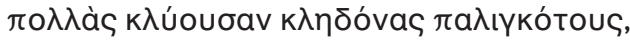

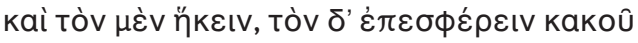

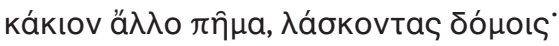

Emplear el lenguaje del llanto y del sueño se presenta como parte de su estratagema persuasiva:

Y para mí se agotaron las fuentes que estallan en llantos, y no me queda ni una sola gota. Tengo dañados mis ojos que tardaban en dormirse por las señales de fuego, siempre desatendidas, que te anunciarían. De los sueños me despertaba por un mosquito que zumbaba ligero, porque veía para vos más sufrimientos del tiempo que acompaña con el sueño. vv. 887-894.

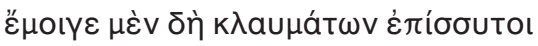

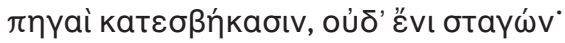

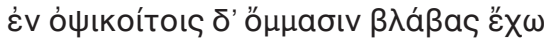

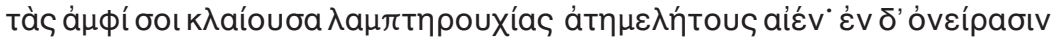

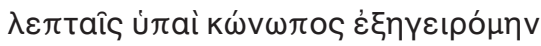

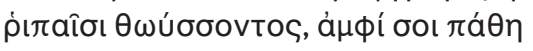

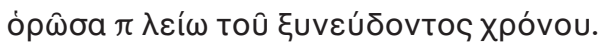

Medda (2017: III 52) señala que las imágenes remiten a la figura de Penélope en Odisea, que se consumía esperando la llegada de Odiseo a Ítaca, pero de forma inversa. Si los sueños de la mujer de Odiseo tenían un carácter placentero (véase, por ejemplo, Odisea 4.795-841), ligados a la llegada del amado, en cambio, los de 
Clitemnestra son una duplicación de las noticias terribles que llegaban a Argos sobre Agamenón. ${ }^{4}$

El abordaje que proponemos respecto de la autoconfiguración de Clitemnestra como mujer que espera a su marido atemorizada y sin poder dormir contrasta con la imagen presentada por el Coro, en los primeros versos de la tragedia, que la muestra como una mujer capaz de gobernar Argos mientras su esposo combate en Troya (vv. 258-260).

Por otra parte, en los versos citados, se genera un contrapunto que refuerza la función que cumple Clitemnestra en el ámbito privado en tanto mujer: las antorchas siempre apagadas, indicadoras de la falta de noticias del rey, son causantes en el ámbito privado del sufrimiento de ella como esposa, insomne en sus aposentos, pero también señalan, en el ámbito público, el peligro de anarquía en la ciudad por la ausencia del rey.

La reina presenta a Agamenón como objeto de sus sentimientos y se refiere a él en tercera persona hasta el v. 877. El pasaje al diálogo directo entre los esposos coincide justamente con el punto más delicado del discurso de Clitemnestra, la ausencia del hijo varón, hecho que impide la unidad familiar (Medda, 2017: III 45):

Por este motivo, nuestro hijo, garantía de nuestra mutua fidelidad, no está aquí presente, como debiera, Orestes. Y no te asombres de eso. Lo cría un huésped y fiel aliado, Estrofio de la Fócide, que me advirtió sobre dos calamidades, el peligro que corrías al pie de las murallas de llión, y que la falta de rey, proclamada por el pueblo, pudiese derribar el consejo, porque es natural para los mortales pisotear aún más al caído. vv. 877-885.

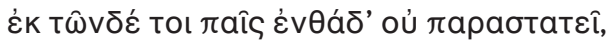

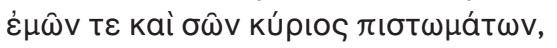

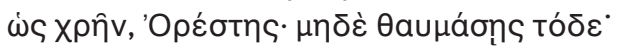

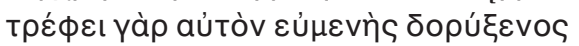

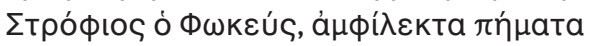

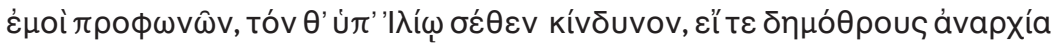

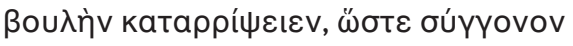

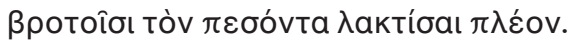

Esquilo no sigue la versión de Píndaro (Pítica 11, vv. 17-18), poeta lírico del siglo VI a. C., que adjudica a la reina, además del crimen de su marido, el tentativo de asesinar a su hijo.

Clitemnestra explica el alejamiento del joven por motivos de prudencia política. Sabe que tiene que ocultar la razón del exilio de su hijo y lo hace de forma tal que parezca que lo ha enviado lejos por miedo a lo que pudiese ocurrir en la ciudad si Agamenón moría en Troya. La reina se escuda aquí en el miedo y el desamparo que tradicionalmente siente una mujer sola, sin el apoyo de ningún varón, y se dirige al Coro nuevamente:

4 Sobre la figura épica de Penélope como paradigma para las mujeres trágicas, véase Foley (2001: 109-144). La autora destaca que Odiseo y su esposa comparten una forma de pensar y de sentir (Odisea 6.181) (Foley, 2001: 128). Se trata de una diferencia fundamental respecto de cómo plantea Esquilo la relación entre Clitemnestra y Agamenón. Sobre la comparación entre Clitemnestra y Penélope, véase Katz (1991), y para un estudio de Penélope como imagen de fidelidad conyugal en Homero, consúltese Zeitlin (1995). 


\begin{abstract}
Ahora, tras haber sufrido todo esto, con el corazón libre de lamentos, podría llamar a este hombre el perro de los establos, la amarra salvadora de la nave, el pilar firme del alto techo, el hijo único para el padre, la vertiente del manantial para el viajero sediento, y la tierra que se le aparece a los navegantes contra toda esperanza, el día bellísimo que se ve después de la tormenta. vv. 895-901.

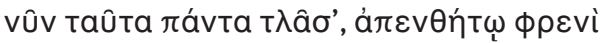

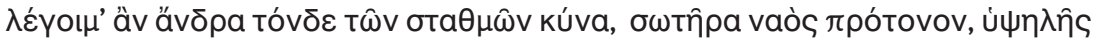

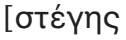

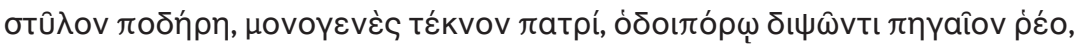

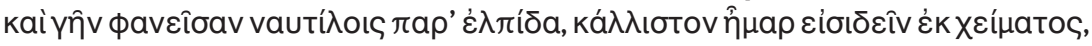

Retoma el tópico de los sufrimientos en ausencia de su marido y vuelve a nombrarlo con una serie de expresiones de dolor y una espesa carga metafórica. Las recientemente citadas son imágenes poéticas elogiosas referidas al marido como defensor de la casa, a las que se adosan otras de tono más elevado, que denotan una mayor intensidad sentimental y expresan la alegría por la superación de un momento difícil.

Finalmente, Clitemnestra le pide a su esposo que descienda del carro y acompaña el pedido de una indicación especial: la de no pisar el suelo, sino el tejido.

Y ahora para mí, querido, baja de este carro, pero no pongas en el piso tu pie, señor, destructor de Troya, vv. 905-907.

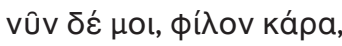

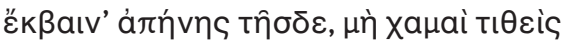

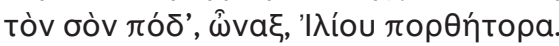

Es la única vez que la reina recurre, ahora dirigiéndose a él en segunda persona, a

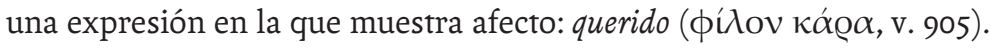

Ante el pedido de avanzar por el tapiz, Agamenón apela a desbaratar el discurso de su esposa, la llama "guardia de mi casa", la compara con un "hombre bárbaro" y aduce que su discurso ha sido demasiado extenso:

Descendiente de Leda, guardia de mi casa, ciertamente hablaste cuanto mi ausencia, pues te extendiste mucho. 5 Pero alabar de modo favorable es un honor que debe llegar de otros. De ninguna manera me trates con delicadeza como a una mujer, ni caigas postrada delante mío con un fuerte grito, como si fueras un hombre bárbaro, ni dispongas un camino que provoque envidia extendiendo prendas, con estas cosas hay que honrar a los dioses. vv. 914-922.

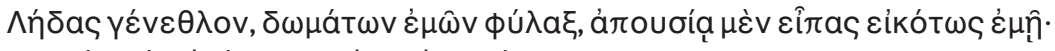

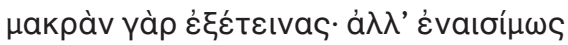

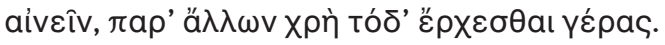

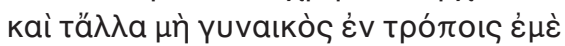

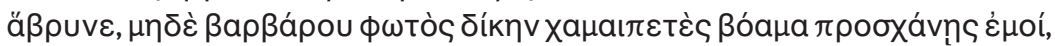

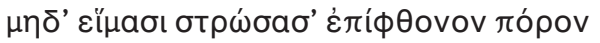

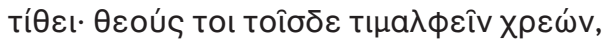


Al llamarla guardia de mi casa, Agamenón señala discursivamente el papel que le compete a ella en tanto mujer y subraya que ha violado no solo su espacio en el hogar sino su posición en la distribución de las tareas asignadas a los géneros sexuales: al alabarlo desmedidamente y al preparar los honores de su llegada, la reina asume un papel exclusivo de los miembros varones de la familia (Crane, 1993: 111). Por otra parte, cabe destacar que, para referirse al discurso de su esposa, Agamenón emplea

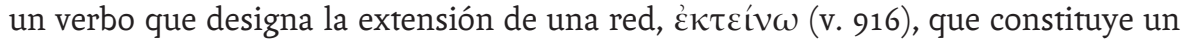
ejemplo de ironía trágica, ya que la red discursiva se materializará fuera del escenario cuando la reina cometa el asesinato.

Luego de tres discursos de considerable extensión, dos a cargo de Agamenón y uno en boca de Clitemnestra, que es el más largo de la tragedia con sus 59 versos, inicia entre ellos un diálogo de tipo esticomítico entre ellos (vv. 931-943). Se trata de un pasaje decisivo, ya que determina la victoria de la reina en el plano discursivo y, también, en el escénico: es un agón desde el punto de vista formal, pero, también, desde su contenido, en tanto se habla de persuasión, victoria y cesión. Recordemos que agón trágico constituye una confrontación verbal entre dos personajes cuya característica principal consiste en la amplitud de relativa de las intervenciones que indica que no es un diálogo. ${ }^{6}$

Ante la negativa del Atrida de caminar por el sendero púrpura, Clitemnestra despliega su capacidad retórica. La reina intenta convencerlo comparándolo con Príamo, el rey de Troya, a quien Agamenón había vencido en la guerra: “¿Pero qué te parece

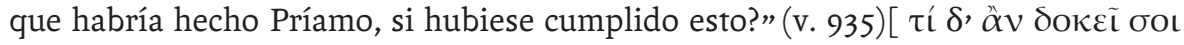

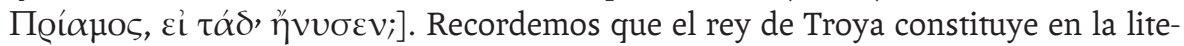
ratura griega antigua el paradigma de la lujuria y el despotismo oriental. Al ver que la comparación como estrategia persuasiva no funciona, Clitemnestra apunta directamente al hecho de que su esposo fue el vencedor de la guerra y establece un juego entre ganar y perder la discusión: "pero a los que son bendecidos también les sienta

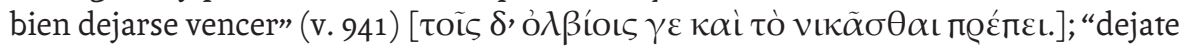

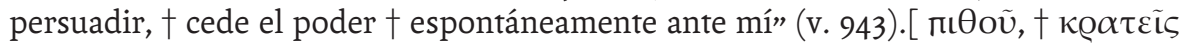

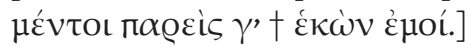

En los vv. 931-943, la inversión que supone mostrar en escena un personaje femenino con atributos masculinos, se indica, por un lado, por la presencia de vocabulario bélico en boca de la propia Clitemnestra y de su marido para describirla (

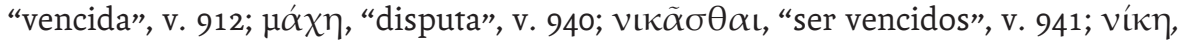

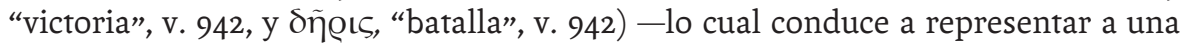
mujer como un guerrero victorioso- $\mathrm{y}$, por otro lado, por el uso por parte de la reina de terminología propia de la persuasión ( $\pi \varepsilon i ́ \theta \omega$, "persuadir", v. 943), cuyo empleo era típico del ámbito público, dominado en Atenas por los hombres. En el cuarto episodio, Casandra refuerza la imagen marcial de Clitemnestra cuando se refiere al llanto por la muerte de Agamenón como "un canto de victoria en la batalla" ( $\omega \varsigma \varsigma$ $\delta$ ' $̇ \pi \omega \lambda \mathrm{o} \lambda u ́ \xi \alpha \tau o$, v. 1236). Por otra parte, también puede considerarse en este sentido

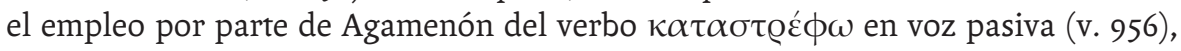
que significa "ser sometido", para indicar su cambio de actitud, ya que se trata de un término que los griegos usaban para hablar de la sumisión de pueblos y ciudades (Medda, 2017: III 88).

6 Acerca de la esticomitia entre los esposos, Medda (2017: I 95) sostiene que lo que resulta decisivo para la victoria de Clitemnestra es haber anulado la distinción entre $\phi \theta$ óvos, "envidia de los dioses", un sentimiento negativo, y $\zeta \tilde{\eta} \lambda$ os, "emulación”, un sentimiento positivo. Véase especialmente el v. 939, “quien no despierta envidia, no es objeto de emulación”

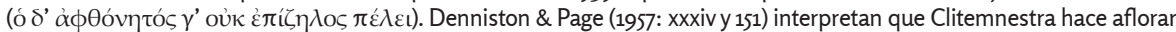
en la escena el verdadero carácter de su esposo. Simpson (1971: 98) sostiene que no hay nada arrogante en las palabras de Agamenón y que en las palabras dirigidas por Clitemnestra a su esposo reside el germen de su venganza. Según Cairns (2002: 194-198), el diálogo contiene los elementos necesarios para modificar la decisión de Agamenón. Sobre el papel de la persuasión en la escena, véase Buxton (1982: 106-108). 
Además, no hay que olvidar el hecho de que ella había ordenado apostar un vigía a la espera de noticias de Troya, que se refiere a su ama como una mujer con la capacidad

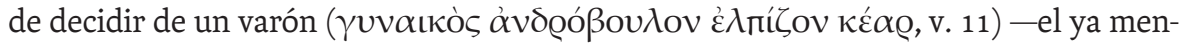
cionado reconocimiento por parte del Coro, en el primer episodio de la tragedia, de su capacidad para gobernar y de su destreza discursiva como propia de un hombre ( $\gamma v ́ v \alpha$,

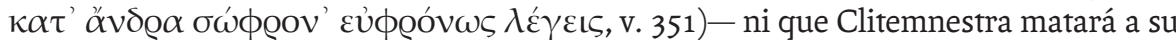
esposo con un arma vinculada al ámbito masculino, ya sea que se trate de un hacha o una espada, como ha discutido la crítica. Se ha discutido mucho sobre el arma empleada por Clitemnestra para cometer el crimen. Podría tratarse de un hacha - como en Electra (v. 99) de Sófocles y Hécuba (v. 1279), Troyanas (vv. 361-362), Electra (vv. 160 y 279) de Eurípides - o de una espada. El hecho de que Von Wilamovitz-Möellendorf (1914: 173 y 1929: 40) se pronunciara por el hacha condicionó a gran parte de la crítica. Sin embargo, en Agamenón, vv. 1262 y 1528-1529, y en Coéforas vv. 1010-10011, se hace una clara referencia a la espada de Egisto y su puesta en disposición para el crimen. El hecho de que Clitemnestra reclame un hacha en Coéforas (v. 809) para defenderse de Orestes no implica que se trate del arma con la que mató a su marido. ${ }^{7}$

\section{La conservación de las cualidades femeninas: el ahorcamiento}

Al mismo tiempo, los discursos aquí estudiados implican la conservación de las cualidades femeninas: Clitemnestra mata como un hombre pero menciona una tentativa de suicidio según la forma femenina, que a su vez es típica de las mujeres fieles, protagonistas de tragedias (Loraux, 1989: 31-32):

A causa de estas noticias adversas, muchas veces otros desataron a la fuerza de mi cuello aprisionado los lazos que apretaban desde arriba. vv. 874-876.

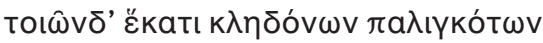

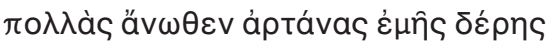

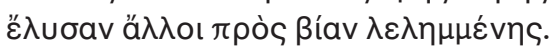

Para poder aproximarnos al asesinato de su marido, que toma la forma de un rito sacrificial, quizá convenga notar que en el v. 908, antes de pedir a Agamenón que baje del carro sin pisar el suelo, Clitemnestra se dirige a las esclavas del palacio para ordenarles que desplieguen el sendero púrpura: "Esclavas, a quienes se les ha asignado la

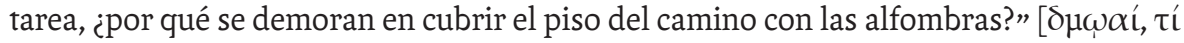

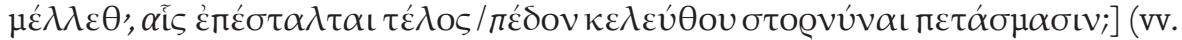
908-909). Después, en tercera persona, dirigiéndose implícitamente a los espectadores, posiblemente, refuerza el pedido, pero agrega un dato: la Justicia guía la acción. ${ }^{8}$

Que se prepare enseguida un sendero púrpura, para que la Justicia lo guíe a la casa que no esperaba volver a habitar. Un pensamiento no vencido por el sueño lo dispondrá con justicia con los dioses, como está decretado. vv. 910-914.

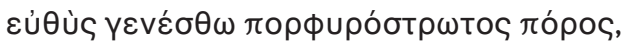

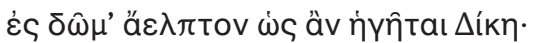

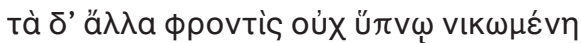

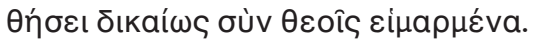

7 A favor de la espada Fraenkel (1962 [1950]: III 806-809) y Medda (2017: I 33); contra Davies (1987: 75) y Sommerstein (1989: 301 ), que abogan por el hacha. Sobre la apropiación de lenguaje épico por parte de la reina, véase Bonnafé (1989).

8 Goldhill (2001 [1986]: 37) señala que díke constituye el término clave para la comprensión del orden social e indica la propia organización de la sociedad como un todo, delineando la recta acción individual y la institución a través de la cual el orden debe ser mantenido. En el caso de Orestía, Agamenón es reconocido como el agente de díke en la destrucción de Troya, y Clitemnestra obedece a díke — según sus propias palabras - en la destrucción de Agamenón (v. 1432). 
¿Quiénes son estas esclavas a las que se dirige Clitemnestra y cómo intervienen desde la puesta en escena? ¿Las esclavas podrían ser las servidoras de la Justicia, que disponen la llegada "con los dioses" y "como está decretado"? Zeitlin (1965: 478) interpreta que las servidoras convocadas por la reina son las Erinias, porque el fantasma de la reina en Euménides se refiere a las ofrendas que ella les había realizado a las diosas (vv. 106-109). Como los muertos no pueden hacer ofrendas, la autora entiende que el rito había sido realizado por Clitemnestra mientras estaba viva. Al referirse a estas deidades, Clitemnestra explicaría la naturaleza de sus juramentos y afirmaría la ley retributiva a partir de la intervención de agentes sobrenaturales para la venganza. Si bien la propuesta de Zeitlin resulta sugerente para el análisis, y sobre todo para una posible puesta en escena, no hay que olvidar que el término registrado en el discurso de la reina es $\delta \mu \omega \eta$, que significa "esclava" o "sirvienta" (Liddell \& Scott, 1996 [1843]: s.v. $\delta \mu \omega \eta$ ), un sustantivo que no sería adecuado para referirse a las Erinias que son figuras divinas. En cuanto a las Erinias, recordemos que son fuerzas primitivas anteriores a los dioses olímpicos, que no se someten a la autoridad de Zeus, y se asocian, por otra parte, al cumplimiento de las leyes. Son divinidades primigenias nacidas de las gotas de sangre derramadas cuando Urano fue mutilado por Cronos (Hesíodo, Teogonía, 183-187 y Apolodoro, Biblioteca, I, I, 4). Su ocupación consiste en provocar la locura a aquellos que asesinaron a un familiar, en especial a los que mataron un progenitor.

En las palabras de Agamenón, pronunciadas un poco más adelante, cuando desciende del carro, se puede notar que ella es quien determina las condiciones de reintegración de su marido al hogar: ${ }^{9}$

Si esto es lo que querés, rápido, que alguno me desate los zapatos, calzado que sirve como esclavo del pie, y mientras yo camino sobre estas telas púrpuras de los dioses, que ninguna mirada envidiosa me golpee desde lejos. Pues tengo mucha vergüenza de arruinar los bienes de la casa con los pies, destruyendo la riqueza y las telas compradas a alto precio. vv. 944-949.

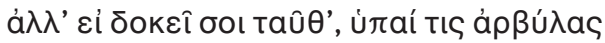

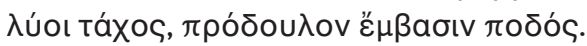

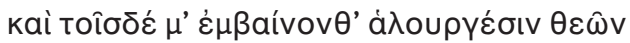

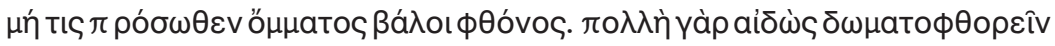

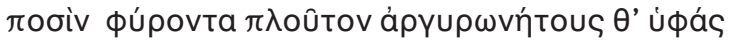

Al finalizar el episodio, probablemente en el momento en el cual Agamenón avanza sobre el tejido, Clitemnestra invoca a Zeus y emplea de forma insistente el verbo $\tau \varepsilon \lambda \varepsilon \tilde{\imath} v$, que significa "cumplir" (vv. 973-974). Se trata de un término que también tiene un significado ritual en relación con el cumplimiento de un sacrificio. Antes de la invocación al dios, la reina presenta a su esposo como "el

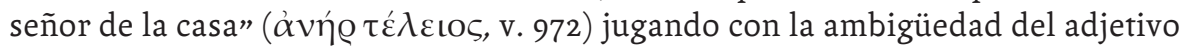
$\tau \varepsilon ́ \lambda \varepsilon \iota 0 \varsigma$, en tanto, además de indicar "de la casa", tiene un sentido ritual, porque se emplea para remitir a la víctima sacrificial. De este modo, con sus palabras finales, alude al papel de víctima que el rey está a punto de cumplir (Medda, 2017: III 89 y 97). Véanse los vv. 1503-1504 en los que Clitemnestra destaca que su esposo fue sacrificado en lugar de los pequeños hijos de Tiestes. Recordemos que en el inicio de la tragedia, el Coro, dirigiéndose a Clitemnestra en segunda persona (aunque seguramente no estando aún ella presente en escena), pregunta qué la apremia y por qué ordena realizar sacrificios por todas partes (vv. 85-86) y. más adelante, en los vv. 260-264, si prepara sacrificios porque han llegado buenas noticias o tiene la esperanza de que lleguen. 
En el último parlamento de Clitemnestra del segundo estásimo, pasaje citado a continuación, se puede ver la insistencia - quizá producto de la ansiedad de Clitemnestra- de dos términos griegos vinculados al hogar: oĩ kos y dónos (vv. 961, 962, 964 y 966, y vv. 968, 971 y 972, respectivamente) y, condensados en los últimos versos, la presencia reiterada de formas del verbo $\tau \varepsilon \lambda \varepsilon \tilde{\imath} \nu$, "cumplir, llevar a cabo un rito". El sacrificio que realizará Clitemnestra sabemos que consiste en la muerte de su esposo:

Existe el mar, ¿quién lo secará? Que nutre de mucha púrpura la preciosa tinta, que siempre se renueva, tintura para los vestidos. El hogar dispone de estos bienes, que tenemos gracias a los dioses, señor, la casa no conoce qué es ser pobre. Habría prometido pisar muchas prendas, si hubiera sido ordenado hacerlo en la sede de un oráculo para la casa, mientras preparaba el rescate de esta vida. Porque, cuando está viva la raíz, el follaje llega a la casa extendiendo una sombra que protege de la canícula. Y tras haber regresado vos al corazón de la casa, el calor de verano llega en el invierno, con tu regreso. Cuando Zeus prepara el vino de las uvas agraces, entonces el frío entra en la casa, si el varón, señor de la casa, la frecuenta. Zeus, Zeus que todo cumplís, cumplí mis plegarias! Preocupate por esto que estás por cumplir. vv. 957-974.

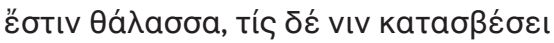

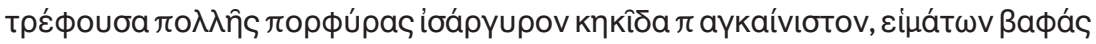

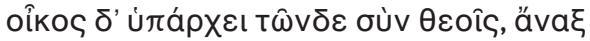

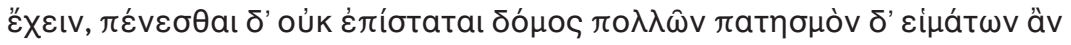

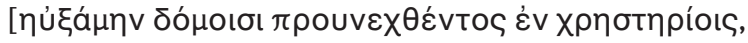

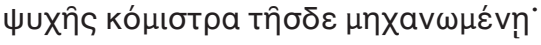

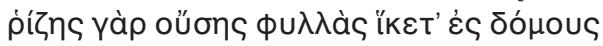

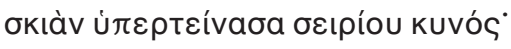

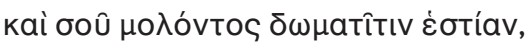

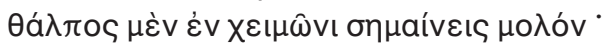

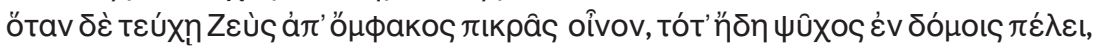

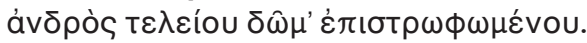

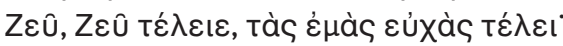

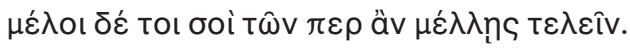

Las dos últimas líneas del discurso tienen la estructura de las fórmulas de cierre de los encantamientos mágicos ( $\phi \theta$ óvoৎ $\delta$ ' $\alpha \dot{n} \sigma \tau \omega$, v. 904, "que se aleje la envidia!"). Ariatta (1975: 121) advierte que el verso constituye una fórmula de exorcismo común entre los griegos. Si la referencia de los vv. 904-913 es a las Erinias, podemos pensar, siguiendo a Zeitlin, que Clitemnestra juega con una doble referencia al invocar a las esclavas y que la marcada alusión a Zeus en el final del episodio, así, forma parte del engaño.

\section{Femenino-masculino: el tejido es una red para matar}

El empleo de una tela púrpura constituye una nueva apropiación subvertida de las tareas asignadas en la sociedad griega para los géneros sexuales. En la Antigua Grecia, el tejido es el objeto por excelencia de la labor femenina, razón por la que constituye uno de los elementos predilectos de los trágicos en las representaciones de los roles femeninos y sus inversiones. ${ }^{10}$ Pensemos, por ejemplo, en el empleo de tejidos por parte de Deyanira en Traquinias (vv. 531-632) y de Filomela en la tragedia fragmentaria Tereo (frs. 581, 586 y 592 Radt), ambas de Sófocles, y de Medea en la obra homónima de Eurípides (vv. 1159-1162).

10 Lyons (2003) analiza los resultados fatídicos de la circulación de bienes preciosos, tanto metales como textiles, cuando las mujeres intervienen, y Lee (2004) estudia la asociación entre el tejido como producto femenino y su empleo para destruir. 
En la Grecia antigua los hombres proveen, para la supervivencia de la familia, artículos provenientes del exterior y las mujeres son las encargadas de transformarlos en fuentes de confort y nutrición (Jenkins, 1985: 110). Clitemnestra está lejos de mostrarse como una protectora de la producción doméstica ya que se trata de "telas compradas a alto precio" (vv. 958-960). Así, por una parte, en la obra se fractura el modelo social en el que el hombre era el encargado de proveer la materia prima a la mujer que debía transformar dichas fibras en el interior del hogar. Por otra, esta tela sale del ámbito privado al ámbito público, se trata de un "objeto maléfico", lo que pretendidamente le permite acceder a su hogar es en verdad un obstáculo para su propio ingreso. Por otra parte, cabe destacar la caracterización de la tela como poikílos, que entendemos aporta una versatilidad que se pone en tensión con la androginia de Clitemnestra. ${ }^{11}$ A continuación, citamos los pasajes en los que se registra el término (marcado en su traducción al español con cursiva):

Para mí, que soy mortal, caminar sobre bellos lienzos coloridos, de ninguna manera puedo hacerlo sin terror. Te pido que me veneres como un hombre, no como un dios. Suena diferente el presagio de las telas para los pies y de las telas coloridas, y no entender mal es el don más grande del dios. vv. 923-927.

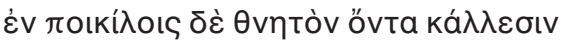

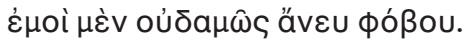

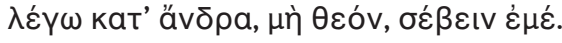

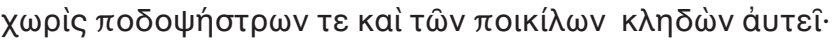

De hecho, me parece que (Príamo) habría caminado sobre los lienzos coloridos. v. 936.

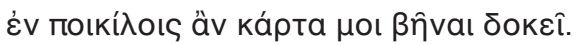

El término poikílos indica el efecto producido por el ensamblaje de diferentes colores y materiales en un objeto, y, también se emplea para expresar ideas más genéricas de variedad, versatilidad y complejidad (Grand-Clément, 2015: 406). ¿Es posible tensar esta versatilidad con la del discurso y performance de Clitemnestra? Liddell \& Scott (1996 [1843]: s.v. noıkílos) definen el término como: "de muchos colores, moteado", "forjado en varios colores, de materiales tejidos o bordados, o en metal" $y$, en sentido metafórico, "cambiante, diverso", "intrincado, complejo", dicho de un laberinto o un oráculo, "intrincado, sutil, abstruso o difícil" y "sutil, astuto, artero" aplicado a Prometeo, Odiseo y las Sirenas, y, finalmente, "cambiante, inestable". Se aplica para tejidos ofrecidos o usados por divinidades, o para telas lujosas y bordadas de origen bárbaro. En el Himno a Afrodita de Safo encontramos un ejemplo paradigmático para nuestro análisis del uso de notkílos por vincular la atracción femenina con el enga-

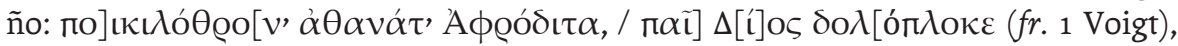
"[Inmortal Afrodita de vestido colorido, hija de Zeus, tejedora de engaños]". Seguimos a Scheid \& Svenbro $(2003,51-72)$ que sostienen que el adjetivo noıkılóӨ̣ovo probablemente se refiere a un "vestido adornado con patrones o apliques florales" en lugar de un "trono adornado" por la evidente relación que existe en la cultura griega entre los tejidos y la poikilía. ${ }^{12}$

Ahora bien, Grand-Clément (2015: 407) señala que la palabra poikílos no solo se aplica a fenómenos visuales, sino que se usa con frecuencia en un sentido metafórico, ya desde el periodo arcaico, circunstancia que entendemos debe ser considerada a la hora de analizar su presencia en un texto trágico, donde el

11 Véase Lee (2004: 262-269) que analiza las imágenes en las tres tragedias que componen Orestía.

12 En lo que atañe a las telas lujosas y bordadas, véase Rinaudo (2009), que estudia el desarrollo semántico y los ámbitos en los que se emplea $\pi$ otkílos y sus derivados desde Homero a Aristóteles. 
juego de ambivalencias y metáforas, se ha demostrado, es constante. Por todo esto, hemos decidido traducir el término como "colorido", en lugar de "bordado" (Perea, Rodríguez Adrados \& Cabellos, 2006 [1982]: 195) o "de varios colores" (De Santis, 2014: 92-93), para marcar un efecto visual de intensidad del color, sin afectar el hecho de que en el texto se aclara que se trata de una tela púrpura. No hemos encontrado un adjetivo en español que, al mismo tiempo, permita expresar el sentido metafórico del término griego.

Es interesante pensar en la posibilidad de tensar la ambigua y variada constitución de la tela, construida por Clitemnestra, con la propia mostración de su carácter y el plurisemantismo de sus palabras en relación con los destinatarios internos de la obra. Detienne \& Vernant (1974 [1991]: 18-20 y 27) vinculan el adjetivo poikílos con la idea griega de inteligencia, la mêtis, concepto definido como la capacidad de saber adaptarse a los eventos a medida que se suceden unos a otros, aquello que permite al débil triunfar sobre el más fuerte. En Homero, el término poikílos se relaciona con el brillo reluciente y el movimiento cambiante que se describen como partes fundamentales de la mêtis, por lo que, cuando el adjetivo se aplica como epíteto, indica que el personaje dispone de ardides y trucos. Si bien tiene una valencia positiva en el poema épico Odisea, ya que poikilómetis es un epíteto de Odiseo, en el género trágico adquiere un valor negativo cuando se aplica a la Esfinge, una figura femenina. En Edipo Rey de Sófocles,

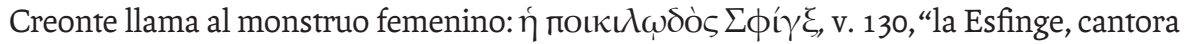
de astucias". En este sentido, el empleo en Agamenón sigue la tendencia de tener un sentido mortífero cuando se refiere a figuras femeninas. En estrecho vínculo con dicha ambigüedad se deriva un nuevo momento en el que dentro de la tragedia se pone a funcionar la ironía trágica: el personaje de Agamenón señala el carácter peligroso de las telas pero no es capaz de advertir que el riesgo es para sí mismo.

\section{La caída de Agamenón}

El género trágico no le agrega simplemente espectacularidad a la narrativa de los poemas épicos. Se trató de un proceso que implicó una transformación en un cuerpo completamente integrado que incluía la presencia física y los movimientos de los actores, los objetos escénicos y escenografía. Taplin (1977: 162) señala que como resultado de la integración los objetos se llenaron de un significado humano, cargados de la complejidad y semanticidad de la narrativa. Esquilo explotó estos recursos desde los inicios del teatro trágico. En este sentido, el sendero púrpura es un objeto que contiene una inmensa potencialidad simbólica y dramática.

La escena de la alfombra representa una contienda de persuasión en la que una mujer le gana al vencedor de la guerra de Troya: ganancia que se manifiesta en el descenso de Agamenón del carro. Clitemnestra reconfigura los alcances del discurso retórico femenino, su androginia expresa en la posición que ocupa en el escenario, en los destinatarios hombres a los que se dirige. Al finalizar el estásimo, la red que Agamenón dice que son las palabras de su esposa se materializa en tejido: el símbolo del quehacer femenino para el mundo griego antiguo es ahora, saliendo del ámbito privado, el instrumento para conducir al rey a la muerte.

\section{Conclusiones}

El personaje de Clitemnestra se representa en Agamenón de un modo intrínsecamente andrógino, en tanto expresa, al mismo tiempo, características y conductas atribuibles a los dos sexos. No sufre un proceso de masculinización a lo largo de la obra, como otras figuras femeninas trágicas. Es el caso de Ágave en Bacantes 
de Eurípides (cfr. Perczyk, 2018: 283-303), obra en la que se además representa la feminización de Penteo, que muere a manos de madre, un proceso que no encontramos en la figura de Agamenón, que se atañe a las normas preestablecidas y así lo expresa en sus discursos.

Al mismo tiempo que se le atribuye a Clitemnestra una capacidad discursiva propia de los hombres, se la ve engañando y sometiendo a los personajes masculinos. Dicha tendencia también continúa en el final, ya que, en su discurso triunfante sobre el cadáver de su esposo, la esposa de Agamenón mezcla el lenguaje y las perspectivas masculinas y femeninas (vv. 1372 y ss.). ${ }^{13}$

Las palabras de la reina son efectivas con Agamenón: ganar discursivamente implica lograr su cometido. De esta manera, su facilidad para la actuación, la simulación y el encantamiento conducen al tópos arcaico de la persuasión femenina. Persuasiva como un hombre y capaz de reformularse según la ocasión, como una mujer, el personaje de Clitemnestra desestabiliza los roles genéricos en lugar de reforzar el orden social, función que, de forma complementaria, llevará adelante la diosa Atenea en la última tragedia de la trilogía Orestía, Euménides (vv. 885-886, 900, 971).

El personaje de la reina, a lo largo de la obra, se autoconstruye, desde el plano lingüístico y el plano escénico, como fluctuante entre dos polos, la autonomía y la dependencia respecto de su marido. Revela en sus palabras su verdadera fuerza, que consiste en la capacidad de adecuarse a la necesidad del momento: oscila entre presentarse en su papel de esposa que sufre y gobernante inteligente. Se dirige al Coro, a su marido, a las esclavas y esto genera diferentes niveles de significación que permite que solo el público advierta con claridad su estratagema. El hecho de que el espectador devele el juego polisémico propuesto, le permite experimentar la conciencia de lo trágico. Los juegos lingüísticos consisten en un in crescendo que llevan al clímax que consiste en la materialización del asesinato de Agamenón.

La capacidad de Clitemnestra para manipular por medio de sus palabras a sus interlocutores masculinos se refleja en el uso del tejido púrpura para conducir al rey hacia la muerte. Así la escena que debería focalizarse en Agamenón y su regreso victorioso al hogar se transforma, en cambio, en el triunfo de una mujer. La oscilación en la configuración genérica de la reina se manifiesta en que, en tanto mujer, apela a argumentos lacrimógenos y privados, usa un vocabulario ritual vinculado a la magia y al cumplimiento de los sacrificios. También, propone una tentativa de suicidio mediante el ahorcamiento, una manera de morir de las mujeres fieles en las tragedias. El empleo de un tejido, producto típico de la actividad femenina que aparece resemantizado, en términos de puesta en escena, concluye en él la ambigüedad del carácter de Clitemnestra. Así, presenta una gran cantidad de rasgos atribuidos a los hombres: organiza claramente su discurso dirigido a destinatarios masculinos; es presentada por Agamenón y, a su vez, se autoconfigura como un general victorioso; se evidencia que ella es la proveedora de la materia prima de sus propios tejidos, y, además, tiene la osadía de ser quien rinde los honores al rey tras su llegada, actividad correspondiente a los hombres. La reina saca al ámbito público el producto de una tarea doméstica que, magnánima y maléfica, se resignifica escénicamente como consecuencia de sus palabras: la red es anticipada en la caracterización de su discurso por parte de Agamenón. Lo que no advierte el rey, en este juego de múltiples destinatarios (él mismo, el coro de ancianos y las esclavas), es quién resulta ser la presa discursiva y material de las palabras y de los planes de Clitemnestra, quien no en vano gobernó Argos durante diez años. 


\section{Dibliografía}

\section{Ediciones y traducciones}

» Ariatta, P. (1975). Esquilo, Agamennone. Torino: Societá Editrice Internazionale.

» Battezzato, L., Di Benedetto, V., Medda, E. \& Pattoni, M. P. (1995). Eschilo, Orestea. Milano: Rizzoli.

»Denniston, J. D. \& Page, D. (1957). Aeschylus, Agamemnon. Oxford: Clarendon Press.

»De Santis, G. (2014). Esquilo, Orestia. Buenos Aires: Losada.

» Fraenkel, E. (1962 [1950]). Aeschylus, Agamemnon, t. I-III. Oxford: University Press.

» Frazer, J. G. (1939). Apollodorus, The Library. London: Heinemann.

» Headlam, W. \& Pearson, A. C. (eds.) (2010). The Agamemnon of Aeschylus, with Verse Translation, Introduction and Notes. Cambridge: University Press.

» Lloyd-Jones, H. (1979). Aeschylus, Oresteia. London: Bloomsbury Academic.

»Lloyd-Jones, H. (1994). Sophocles, Ajax, Electra, Oedipus Tyrannus. Cambridge: Harvard University Press.

» Lucas de Dios, J. M. (1983). Sófocles, Fragmentos. Madrid: Gredos.

" Medda, E. (2017). Eschilo, Agamennone, t. I-III. Roma: Bardi Edizioni.

» Munro, D. B. \& Allen, T. W. (1963 [1908]). Homeri Opera, Odyssey libros continens I-XII, t. III. Oxford: Clarendon Press.

» Munro, D. B. \& Allen, T. W. (1963 [1908]). Homeri Opera, Odyssey libros continens XIII-XXIV, t. IV. Oxford: Clarendon Press.

»Page, D. L. (ed.) (1972). Aeschyli Septem quae supersunt Tragoedias. Oxford: Clarendon Press.

»Perea, B., Rodríguez Adrados, F. \& Cabellos, B. (2006 [1986]). Esquilo, Tragedias. Madrid: Gredos.

»Radt, S. (2009). Tragicorum Graecorum Fragmenta, t. III, Aeschylus. Göttingen: Vandenhoeck \& Ruprecht.

»Snell, B. \& Maeler, H. (1980). Pindari carmina cum fragmentis. Leipzig: Teubner.

»Solmsen, S. (1979). Hesiodi opera. Oxford: University Press.

»Untersteiner, M. (1946-1947). Eschilo, Le tragedie, t. I-II. Milano: Istituto Editoriale Italiano.

»Voigt, E. M. (1971). Sappho et Alcaeus. Amsterdam: Polak \& van Gennep.

\section{Bibliografía secundaria}

"Bachofen, J. J. (1992 [1861]). El matriarcado: una investigación sobre la ginecocracia en el mundo antiguo según su naturaleza religiosa y jurídica. Madrid: Akal. 
»Bierl, A. (2017). “Klytaimestra Tyrannos: Fear and Tyranny in Aeschylus's Oresteia (with a Brief Comparison with Macbeth)". Comparative Drama 51.4, 528-563.

» Bonnafé, A. (1989). “Clytemmestre et ses batailles: Éris et Peitho”. En Étienne, R. (ed.) Architecture et poésie dans le monde grec. Hommage à Georges Roux (pp. 149-157.). Lyon: Maison de l'Orient.

"Buxton, R. (1982). Persuasion in Greek Tragedy, A Study of Peitho. Cambridge: University Press.

»Cairns, D. L. (2002). Aidōs. The Psychology and Ethics of Honour and Shame in Ancient Greek Literature. Oxford: University Press.

»Davies, M. (1987). “Aeschylus' Clytemnestra, Sword or Axe?”. Classical Quaterly 37, 65-75.

»Detienne, M. \& Vernant, J. P. (1978). Cunning Intelligence in Greek Culture and Society. Chicago: University Press.

»Doyle, A. (2008). "Cassandra: Femenine Corrective in Aeschylus' Agamemnon”. Acta Classica 51, 57-75.

» Foley, H. P. (2001). Female Acts in Greek Tragedy. Princeton: University Press.

» Goldhill, S. (1984). Language, Sexuality, Narrative. The Oresteia. Cambridge: University Press.

» Goldhill, S. (2001 [1986]). Reading Greek Tragedy, Cambridge: University Press.

» Grand-Clément, A. (2015). “Poikilia”. En Destrée, P. \& Murray, P. (eds.) A Companion to Ancient Aesthetics (pp. 406-421). Oxford: Wiley Blackwell.

» Jenkins, I. (1985). La vida cotidiana en Grecia y Roma. Madrid: Akal.

" Katz, M. A. (1991) “The House of Atreus Story and Penelope's Kyrieia (Books 1-4)" y "Penelope and Clytemnestra: The First Nekya (Book 11)". En Penelope's Renown: Meaning and Indeterminacy in the Odyssey (pp. 29-53). Princeton: University Press.

"De Lauretis, T. (1989). “La tecnología del género”. Mora 2, 6-34.

» Lee, M. M. (2004). ““Evil Wealth of Raiment”: Deadly Péploi in Greek Tragedy”. The Classical Journal 99, 253-279.

"Loraux, N. (1989). Maneras trágicas de matar a una mujer. Madrid: Visor.

»Lyons, D. (2003). "Dangerous Gifts: Ideologies of Marriage and Exchange in Ancient Greece”. Classical Antiquity 22.1, 93-134.

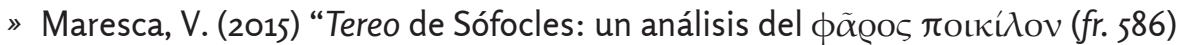
y la mêtis femenina". En Actas del Séptimo Coloquio Internacional, "[Una] nueva visión de la cultura griega antigua en el comienzo del tercer milenio: perspectivas y desafíos", Ensenada, Instituto de Investigaciones en Humanidades y Ciencias Sociales, Facultad de Humanidades y Ciencias de la Educación, Universidad Nacional de La Plata, [en línea]. Consultado el 2 de septiembre de 2019: http://coloquiointernacionalceh.fahce.unlp.edu.ar.

" McClure, L. (1999). “Logos Gunaikos: Speech and Gender in Aeshylus' Oresteia". En Spoken Like a Woman: Speech and Gender in Athenian Drama (pp. 70111). Princeton: University Press.

»Perczyk, C. J. (2018). La locura en Heracles y Bacantes de Eurípides. Buenos Aires: Miño \& Dávila.

»Rinaudo, M. (2009) “Sviluppi semantici e ambiti d’uso di ґoเkílos e derivati, 
da Omero ad Aristotele”. En Berardi, E., Lisi, F. L. \& Micalella, D. (eds.) (2009). Poikilia: variazioni sul tema (pp. 25-63). Roma: Bonnano.

"Sevieri, R. (1991). “Linguaggio consapevole e coscienza individuale di Clitennestra nell' Agamennone di Eschilo". Dioniso 61, 13-31.

"Simpson, M. (1971). “Why does Agamemnon Yield?’”. La Parola del Passato 26, 94-101.

»Sommerstein, A. H. (1989). “Again Klytaimestra’s Weapon”. Classical Quaterly 39, 296-301.

» Taplin, O. (1977). The Stagecraft of Aeschylus, The Dramatic Use of Exits and Entrances in Greek Tragedy. Oxford: University Press.

»Scheid, J. \& Svenbro, J. (2003). Le métier de Zeus, Mythe du tissage et du tissu dans le monde gréco-romain. Paris: Errance.

» Vernant, J. P \& Vidal Naquet, P. (1987). Mito y tragedia en la Grecia antigua I. Barcelona: Taurus.

»Winnington-Ingram, R. P. (1948). "Clitemnestra and the Vote of Athena". The Journal of Hellenic Studies 68, 130-147.

»Von Wilamovitz-Möellendorf, U. (1914). Aischylos, Interpretationem. Berlin: Weidmannsche Buchhandlung.

"Zeitlin, F. (1965). "The Motif of the Corrupted Sacrifice, Aeschylus' Oresteia". Transactions and Proceedings of the American Philological Association 96, 463508.

"Zeitlin, F. I. (1978). “The Dynamics of Misogyny: Myth and Mythmaking in the Oresteia”. Arethusa 11, 170-84.

»Zeitlin, F. I. (1990). "Patterns of Gender in Aeschylean Drama: Seven against Thebes and the Danaid Trilogy". En Griffith, M. \& Mastronarde, D. J. (ed.) Cabinet of the Muses, Essays on Classical and Comparative Literature in Honor of Thomas G. Rosenmeyer (pp. 103-115). Atlanta: Scholars Press.

"Zeitlin, F. I. (1995). “Figuring Fidelity in Homer's Odyssey”. En Cohen, E. (ed.) The Distaff Side: Representing the Female in Homer's Odyssey (pp. 117-152) Oxford: University Press.

\section{Instrumenta studiorum}

» Liddell, H. G. \& Scott, R. (1996 [1843]). Greek-English Lexicon. Oxford: Clarendon Press. 